\title{
Winter sleep with room service: denning behaviour of brown bears with access to anthropogenic food
}

\author{
M. Krofel, M. Špacapan \& K. Jerina \\ Department of Forestry and Renewable Forest Resources, Biotechnical Faculty, University of Ljubljana, Ljubljana, Slovenia
}

\author{
Keywords \\ hibernation; denning behaviour; supplemental \\ feeding; anthropogenic food; Ursus arctos; \\ meta-analysis; brown bear.

\section{Correspondence} \\ Miha Krofel, Department of Forestry and \\ Renewable Forest Resources, Biotechnical \\ Faculty, University of Ljubljana, Večna pot 83, \\ SI-1001 Ljubljana, Slovenia \\ Email: miha.krofel@gmail.com \\ Editor: Matthew Hayward
}

Received 3 June 2016; revised 23 September 2016; accepted 12 October 2016

doi:10.1111/jzo.12421

\begin{abstract}
Large quantities of food subsidies provided by humans to animal communities have the potential to change a variety of animal life traits, including denning behaviour of facultative hibernators like bears. Brown bears Ursus arctos regularly use anthropogenic food, but it has remained unclear if human food subsidies affect their hibernation and denning behaviour, despite the consequences this could have for bear interactions with humans and other species. We studied denning behaviour of European brown bears in Slovenia, where intensive supplemental feeding with corn is practiced throughout the year, including winter. We used GPS telemetry data to locate den sites and to monitor bear denning chronology. We conducted a meta-analysis to compare our results with other bear populations across Europe, Asia and North America. A consistent relationship between latitude and time spent denning was observed for male and female brown bears across the species' range (for each degree of latitude northwards, denning period increased for 3.1 days), and males on average denned 10.3 days longer than females throughout the latitudinal gradient. However, our study area deviated strongly from regions where supplemental feeding was not practiced. In Slovenia, denning period averaged 82 days for females and 57 days for males, which was 45 and 56\% shorter compared to the time predicted for this latitude, respectively. We also observed regular den abandonments (61\% of bears abandoned dens, on average 1.9 times per winter). During the winter period bears increased use of supplemental feeding sites for $61 \%$ compared to the non-denning period. We conclude that the availability of anthropogenic food is an important driver of denning behaviour in brown bears. Reduction in the denning period increases the potential for bear interactions with other species, including humans, and we highlight possible management and ecological implications of this human-caused perturbation to denning behaviour of wild ursids.
\end{abstract}

\section{Introduction}

Several mammalian species have evolved unique physiological adaptations to conserve energy when food supplies are scarce and ambient temperatures are low (Florant \& Healy, 2012). In some species hibernation is maintained even when food is available (obligate hibernators), whereas other species remain active in response to increased food availability (facultative hibernators) (Harlow, 1995).

Large amounts of food subsidies provided intentionally or unintentionally by humans to animal communities across the world ecosystems (Oro et al., 2013) have the potential to modify hibernation patterns in facultative hibernators. There is increasing evidence that anthropogenic food sources change a variety of animal life traits, including genetic and reproductive parameters, abundance, survival, spatial distribution as well as intra- and inter-specific interactions (for review see Oro et al., 2013; Newsome et al., 2015). However, effects of this relatively novel food resource on facultative hibernators in the wild remain poorly understood and often overlooked when wildlife feeding practices are designed.

Ursids are among the most studied facultative hibernators, but despite decades of extensive research, complex mechanisms that drive bear denning behaviour in the wild remain unclear (Hellgren, 1998; Manchi \& Swenson, 2005; Graham \& Stenhouse, 2014). Bears exhibit several characteristics, such as lower reduction in body temperature, that separate them from the deep hibernation of many other mammals (Hissa, 1997; Hellgren, 1998; Evans et al., 2016). Hibernation typically takes place in winter dens, which bears use to reduce energy loss when food is inadequate (Tietje \& Ruff, 1980) and for pregnant females to give birth (López-Alfaro et al., 2013).

A large range distribution and persistence in a variety of ecological settings makes the brown bear Ursus arctos a suitable species for studying denning behaviour and factors affecting it. Latitude explains part of the variability in the length of denning period, but additional intrinsic (e.g. sex, age, reproductive state, fat reserves) and external factors also play a role 
(Hissa, 1997; Manchi \& Swenson, 2005; Graham \& Stenhouse, 2014). Autumn food availability and early snowfall are the most frequently reported external triggers of denning (Linnell et al., 2000), although researchers from different regions often came to different conclusions about their effects (e.g. Schoen et al., 1987; Clevenger, Purroy \& Pelton, 1990; Van Daele, Barnes \& Smith, 1990; Haroldson et al., 2002; Manchi \& Swenson, 2005). Nevertheless, there is general agreement that lack of food during winter is the primary cause for denning of non-pregnant brown bears (Ciarniello et al., 2005). This is supported with observations of non-denning bears in areas where abundant natural food sources are available also late in season or even throughout the winter, such as salmon on Kodiak Island in Alaska (Van Daele et al., 1990).

Because brown bears readily consume human-provided food when they can access it (Peirce \& Van Daele, 2006; Kavčič et al., 2015), availability of anthropogenic food sources during the winter period could affect their denning behaviour, as has already been reported for the American black bear Ursus americanus (Beckmann \& Berger, 2003; Dobey et al., 2005). This might have further ecological and management consequences as shortening bear denning periods could increase inter-specific interactions within the carnivore guild (Krofel \& Jerina, 2016), as well as bear interactions with humans and consequently human-related mortality of bears (Rayl et al., 2014; Evans et al., 2016). Especially in Europe, corn and other anthropogenic food is often intentionally provided to bears at wildlife feeding sites (Kavčič et al., 2013). Supplemental and diversionary feeding of bears are controversial practices that are used for various purposes, including bear hunting, ecotourism and reduction in human-bear conflicts, but they have also been associated with several unwanted side-effects (Penteriani, Delgado \& Melletti, 2010; Steyaert et al., 2014; Kavčič et al., 2015). While some researchers raised concern about possible effects that supplemental feeding could have on bear denning behaviour (Kavčič et al., 2015), others assumed the impact might be negligible (Skuban, Find'o \& Kajba, 2016). Surprisingly, to our knowledge no published study exists on the effects of supplemental feeding or other anthropogenic food sources on brown bear denning behaviour.

We studied denning behaviour of European brown bears in Slovenia, where intensive supplemental feeding is practiced throughout the year in a dense network of feeding sites. This anthropogenic food represents one of the key food sources for local bear populations (Kavčič et al., 2015). We used GPS telemetry data to locate den sites, estimate den entry and emergence dates, total denning period and den abandonment rates. We also analysed habitat use of Slovenian bears that were active during the winter to study their potential use of supplemental feeding sites during winter and compare it to other seasons. Next, we reviewed published data on bear denning behaviour from other brown bear populations. We conducted a meta-analysis to predict the expected denning period of both sexes for the latitude of our study area. If supplemental feeding affects bear denning behaviour, then time spent in the den should be shorter in Slovenia compared to denning periods for bears in studies from regions without supplemental feeding.

\section{Materials and methods}

\section{Study area}

The study was conducted in the Dinaric Mountain Range in Slovenia $\left(45^{\circ} 25^{\prime}-45^{\circ} 47^{\prime} \mathrm{N}, 14^{\circ} 15^{\prime}-14^{\circ} 50^{\prime} \mathrm{E}\right)$ in mixed temperate forests dominated by fir and beech. The altitudes range from 200 to $1800 \mathrm{~m}$. The limestone and dolomite geology of the area result in a rugged karstic relief and abundant karstic structures, such as rock crevices, horizontal caves, rock shelters and dolines. The average density of recorded caves in the study area is 1 cave $/ \mathrm{km}^{2}$, with local extremes of up to 40 caves $/ \mathrm{km}^{2}$ (http://www.katasterjam.si). The annual temperature averages $5-8^{\circ} \mathrm{C}$ with monthly temperatures ranging from -3 to $0^{\circ} \mathrm{C}$ in January and 15 to $20^{\circ} \mathrm{C}$ in June. Annual precipitation averages between 1400 and $3500 \mathrm{~mm}$ across the study area. Snow cover lasts from 50 days at $500 \mathrm{~m}$ and up to several months at higher elevations. The vegetative growth period lasts from late April to late October (Kavčič et al., 2015).

Supplemental feeding of bears is intensive and has been practiced in some parts of Slovenia for over 100 years. Highenergy supplemental food, especially corn (Fig. 1), is provided to bears year-round and in large quantities (12 500 kg/ $100 \mathrm{~km}^{2}$ annually) at numerous feeding sites (on average one feeding site per every $2.7 \mathrm{~km}^{2}$ ) (Krofel \& Jerina, 2016). Supplemental food represents $34 \%$ of dietary energy content ingested by the bears in this area. Other important natural foods include: insects (21\%), hard mast (mainly beechnuts; $18 \%$ ), fruits $(16 \%)$ and wild ungulates (7\%) (Kavčič et al., 2015). Bears in Slovenia often use natural caves for denning (e.g. Supporting Information Fig. S2).

\section{Bear capture, telemetry, monitoring of denning events and use of feeding sites}

In 2005-2009 we captured 33 adult brown bears using Aldrich foot snares or by darting from a high stand according to

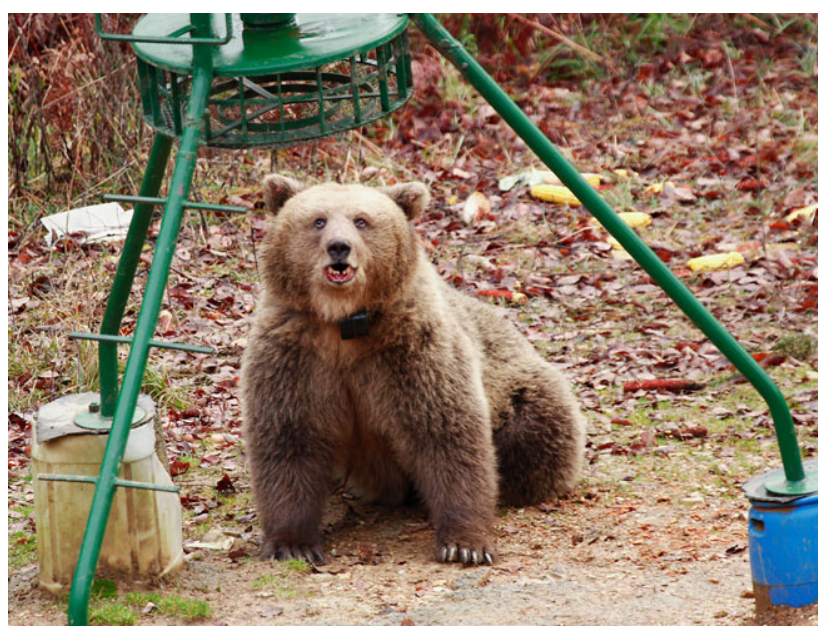

Figure 1 Radio-collared female brown bear Ursus arctos at the bear feeding site with corn in Slovenia. Photo: M. Krofel. [Colour figure can be viewed at wileyonlinelibrary.com]. 
standard protocols (see Jerina et al., 2012 for details). Bears were fitted with 3D GPS (Global Positioning System) collars (850 g; Vectronic, Germany and Lotek, USA). Collars were programmed to attempt a GPS fix every hour and to monitor the animal's activity in 5-min intervals. All collars were equipped with timer-controlled drop-off mechanisms set to activate after 1 year. Several of the monitored bears died (5 shot, 1 road kill), removed collar $(N=4)$ or collar failed $(N=6)$ before or during the denning period; therefore, data from 17 bears ( 5 males, 12 females) were used for further analysis of denning behaviour.

We used location and activity data acquired from GPS collars to locate potential den sites and determine den entry and exit dates, following procedures described by Evans et al. (2012). We visited and characterized all den sites (i.e. cave, rock shelter or bed in dense vegetation) after bears had left the area. Rock shelters were defined as den sites under overhanging rock, but without shelter provided from the sides. In contrast, caves provided shelter from all three sides except towards the entrance of the cave. We defined arrival at a den as the first GPS location within the cluster of GPS locations or in the series of unsuccessful GPS fixes indicating entrance into a cave. We considered den use to have begun at the time of the first inactive period following arrival to the den site. We used first location outside of a den site after the last location in that den as the date of abandonment. Following Rayl et al. (2014) we did not classify occasional activity bouts, when a bear exited a den for a short period of time to the vicinity of den and then re-entered the same den, as abandonment. A den was considered as abandoned only, when at least two GPS locations were $>1 \mathrm{~km}$ from the den site to avoid potential errors in GPS fixes. We defined a denning period as the total number of days spent inside a den or dens during a given winter.

We considered a bear to be present at the feeding site if a GPS location was within $140 \mathrm{~m}$ of the centre of the feeding site.

\section{Meta-analysis of length of the bear denning period}

We searched for previous studies on brown bear denning using search terms "Ursus arctos" AND ["den" OR "denning"] in Scopus (scopus.com) literature database. We also searched in the literature-cited sections of all retrieved articles. Due to the strong effect of sex on bear denning periods, we retained only studies $(N=14)$ that provided information on denning behaviour separately for males and females (Supporting Information Table S3). In females, reproductive status can affect denning period, but as several studies did not report or lacked data on reproductive status, we pooled data for all females. All previous studies came from the regions without supplemental feeding or other reported important anthropogenic food sources.

For each study area we extracted values of latitude and length of the denning period for each sex. First, we visually inspected data on a scatterplot and assessed potential outliers. In general, length of the denning period was linearly increasing with latitude in both sexes, except for the three obvious outliers (males in SW Kodiak and both sexes in Slovenia; Fig. 2). We used general regression models (GRM) to test whether these records are genuine outliers and to estimate their deviation from expected values according to the latitude of given

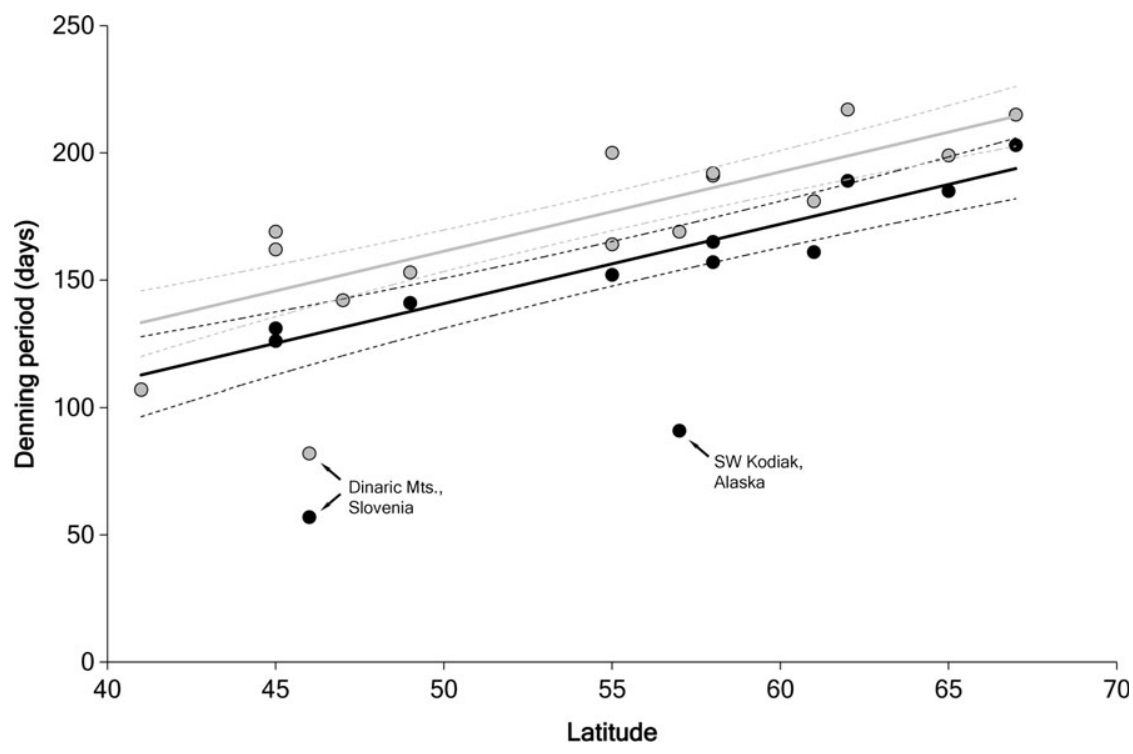

Figure 2 Length of the denning period in respect to the latitude for male (black) and female (grey) brown bears Ursus arctos across Europe, Asia and North America. Dots represent actual values and lines results of the general regression model (solid lines for average values and dotted lines limits of 95\% confidence intervals). Three outliers are indicated by arrows. Data sources: Servheen (1983), Schoen et al. (1987), Clevenger et al. (1990), Miller (1990), Van Daele et al. (1990), Friebe, Swenson \& Sandegren (2001), Haroldson et al. (2002), McLoughlin, Cluff \& Messier (2002), Seryodkin et al. (2003), Ciarniello et al. (2005), Manchi \& Swenson (2005), Mertzanis et al. (2005), Graham \& Stenhouse (2014) and this study. For details see Supp. Mat. 2. 
study area. Length of the denning period was used as a dependent variable, latitude as independent covariate and sex as a factor. As an explanatory variable we also included interaction latitude $\times$ sex to test homogeneity of the slopes between the sexes. We built a full GRM, which was progressively reduced using a backward algorithm until we obtained the best model. We removed outliers (values with standard residual $>1.96$ ) and repeated the procedure described above. For the final model we calculated mean values and $95 \%$ confidence intervals (CI) and estimated deviations of the outliers from expected values.

\section{Results}

\section{Denning behaviour of brown bears in Slovenia}

Male and female brown bears spent on average $( \pm \mathrm{SE})$ $57 \pm 12$ days (range: $17-90 ; N=5$ ) and $82 \pm 11$ days (range: $10-142 ; \quad N=12$ ) denning per winter, respectively. Among females with known reproductive status, pregnant females and females that entered dens with cubs spent on average $94 \pm 10$ days (range: $72-142 ; N=4$ ) and $83 \pm 12$ days in dens (range: $10-137 ; N=6$ ), respectively.

Mean den entry date was 1 December (range: 22 October31 December) and mean final den emergence was 6 March (range: 17 January-16 April). Males entered dens on average later (5 December) than females (29 November) and emerged earlier (males: 18 February; females: 13 March). Pregnant females entered dens earlier (23 November) than females that entered dens with cubs (8 December), but emergence dates were similar (females giving birth: 11 March; females with yearlings: 14 March).

We documented 21 den abandonment and re-denning events. Den abandonment occurred at least once in $61 \%$ of the 17 bear-winters and during these, bears abandoned and re-denned on average, 1.9 times per winter (range: 1-4). The proportion of winters with den abandonment was similar between males $(60 \% ; N=5)$ and females $(62 \% ; N=12)$. Males that abandoned dens did so 2.7 times per winter and females 1.6 times per winter.

Most of the bears were denning in karstic caves (17 of 23 den sites; see Supporting Information Tables S1 and S2 for measurements and other characteristics of used caves), rock shelters $(N=6)$ and one male denned in an open den site in a dense spruce stand, where a nest was created from spruce twigs. Bears stayed in the dens longer when using caves (mean + SE: $65 \pm 10$ days; range: $3-137$ ) than in the rock shelters (mean: $11 \pm 5$ days; range: $3-35$ ) or in dense spruce stand (10 days).

\section{Comparison of bear denning behaviour with other study areas}

After removal of the three outliers, the meta-analysis of literature data revealed a consistent relationship between latitude and time spent denning for male and female brown bears across study areas from Europe, Asia and North America $\left(N=24 ; \quad R^{2}=0.80 ; \quad P<0.001 ; \quad\right.$ Fig. 2$)$. The final model
(Table 1) predicts that across the species' range, length of the denning period is on average 10.3 days (CI: 4.5-16.0 days) shorter in males compared to females and that for each degree of latitude northwards, the denning period increases by 3.1 days (CI: 2.4-3.9 days). Interaction between sex and latitude was non-significant $(P=0.88)$. Model residuals did not deviate from the normal distribution, did not indicate any pattern along the latitude and were homogenous between both sexes.

Three obvious outliers deviated from the general pattern (Fig. 2): bears of both sexes in our study area in Slovenia and males in SW Kodiak, Alaska (standard residual: -2.38 to -2.05). In Slovenia, the denning period length for females was $45 \%$ (CI: $41-48 \%$ ) or 67 days (CI: $57-77$ days) shorter and for males, $56 \%$ (CI: $51-59 \%$ ) or 71 days (CI: 59-83 days) shorter compared to the time expected for this latitude. SW Kodiak males spent $44 \%$ (CI: $41-47 \%$ ) or 72 fewer days (CI: 63-80 days) in dens than predicted by the model for the latitude of that study area.

\section{Use of supplemental feeding sites}

All bears tracked with telemetry $(N=33$ bears, 61636 GPS locations) regularly used supplemental feeding sites throughout the year. On average, bears spent $8.4 \%$ of their time at the feeding sites. During the average denning period (1 December6 March) when bears were outside the dens, use of feeding sites increased by $61 \%$ compared to the non-denning period (7.2 and $11.7 \%$ of time was spent at feeding sites during the non-denning and denning period, respectively). [Correction added on 20 December 2016, after first online publication: In the preceding sentence, the denning and non-denning periods were in the wrong order and have been corrected in this current version.] When considering only periods when bears were outside the den, monthly use of feeding sites was highest in January, when bears spent $18 \%$ of their time at feeding sites.

\section{Discussion}

Review of the brown bear denning periods across the species' range distribution indicated consistent patterns in the relationship between latitude and denning duration (Fig. 2). Two study areas notably diverge from this pattern. The first is the Terror Lake region in the SW part of Kodiak Island in Alaska, USA, which is exceptional due to locally abundant and high-energy food source (salmon) available during first part of the winter (Van Daele et al., 1990). The second study area deviating from the

Table 1 Parameter estimates and test statistics for the general regression model explaining time brown bears spent denning $(N=24)$

\begin{tabular}{lcrrrr}
\hline & Estimate & \multicolumn{1}{c}{$\beta$} & \multicolumn{1}{c}{ LCL } & \multicolumn{1}{c}{ UCL } & \multicolumn{1}{c}{$P$} \\
\hline Sex (M vs. F) & -10.3 & -0.36 & -16.1 & -4.5 & 0.001 \\
Latitude & 3.1 & 0.86 & 2.4 & 3.9 & $<0.001$ \\
Intercept & -5.1 & & -46.7 & 36.5 & 0.801 \\
\hline
\end{tabular}

LCL, lower 95\% confidence level; UCL, upper 95\% confidence level. $R^{2}=0.80$. 
general pattern is Slovenia, where we observed a $45-56 \%$ shorter denning period than expected for this latitude. We believe that the most likely explanation for this observed deviation is intensive supplemental feeding of bears with corn that is available at numerous feeding sites throughout the winter.

This conclusion is supported by the habitat use of bears that were active during the general denning period (early December-early March). These bears even intensified their use of the feeding sites compared to other seasons. Reliance on anthropogenic food from the feeding sites during winter is further supported by results of the diet analysis from our study area, where all scats found in winter consisted entirely of food derived from the feeding sites (Kavčič et al., 2015).

Besides the short denning season, we observed that the majority $(61 \%)$ of bears regularly abandoned their dens during the denning period. Den abandonment is occasionally reported in other brown bear populations and other hibernating ursid species, but they are usually connected with den disturbance by humans or flooding (Amstrup, 1993; Huber \& Roth, 1997; Oli, Jacobson \& Leopold, 1997; Swenson et al., 1997; Linnell et al., 2000; Rayl et al., 2014). A notable exception reported in the brown bear literature is again the Terror Lake region of the Kodiak Island with high food availability in early winter, where $18 \%$ of the studied bears disrupted denning and further $10 \%$ did not den at all (Van Daele et al., 1990). Food-related disruption of denning is occasionally reported from the southern regions (Clevenger et al., 1990; Huber \& Roth, 1997; Naves, Fernández-Gil \& Delibes, 2001; Nores et al., 2010), where natural food is sometimes available throughout the winter (Clevenger, Purroy \& Pelton, 1992). Similarly, bears in captivity sometimes do not den if fed throughout the winter (Schoen et al., 1987).

Disturbance-related den abandonment affects males and females equally (Swenson et al., 1997), while male-biased den abandonment is more typical for food-related causes (Van Daele et al., 1990; Wooding \& Hardisky, 1992). We observed increased den abandonment frequency and a greater reduction in denning period in males. Therefore, we assume that the high rates of den abandonment and shorter denning period in Slovenia were not connected with disturbance. Instead, we suggest that bears are aware of supplemental food available at the feeding sites during winter and disrupt denning to feed on this anthropogenic food source. A similar explanation was suggested for the shortened denning period in Florida, where American black bears regularly used corn provided for the white-tailed deer Odocoileus virginianus during winter (Wooding \& Hardisky, 1992; Dobey et al., 2005).

Although our sample size was relatively small (17 bears), the observed effect of supplemental feeding on bear denning behaviour is not unexpected. Lack of food availability is the primary reason for hibernation, which serves as an energy-saving strategy (Tietje \& Ruff, 1980; Ciarniello et al., 2009). When food is available throughout the winter, the need for denning is reduced. During the last century, bears in Slovenia have evidently adapted to the novel anthropogenic food source provided through supplemental feeding. This supports the importance of winter food availability being an important factor influencing denning behaviour in facultative hibernators (Harlow, 1995).

\section{Management implications}

Human-caused perturbations to brown bear denning behaviour have largely been connected with disturbance of den sites (Schoen et al., 1987; Swenson et al., 1997; Linnell et al., 2000) and climate change (Servheen \& Cross, 2010; Evans et al., 2016). Our study indicates that humans can affect bear denning chronology also through the provision of anthropogenic food. A substantial reduction in the denning period, which we observed in a population subjected to intensive supplemental feeding, could have important management and ecological implications.

Prolonged winter activity increases the period when bears can come into contact with people and thus increases the potential for human-bear conflicts and human-caused bear mortality. A similar link between human-bear conflicts and shorter denning period due to climate change has been suggested by several researchers (Servheen \& Cross, 2010; Pigeon, 2011; Rayl et al., 2014; Evans et al., 2016). Furthermore, bear reproductive rates are strongly linked to energy reserves during hibernation and food availability immediately after hibernation (López-Alfaro et al., 2013). Foraging on abundant anthropogenic food during and after winter could artificially increase reproduction and local bear densities. This could elevate the potential for conflicts or increase the need for bear culling with possible further negative consequences (Krofel, Jonozovič \& Jerina, 2012). On the other hand, it must also be noted that bears in Slovenia spent a large part of their active winter time at the feeding sites and were thus diverted from human settlements, which likely reduced the potential for conflicts with people in residential areas during winter.

Beside increased potential for human-bear interactions, shortened bear denning periods may trigger trophic cascades in the ecosystems. For example, it has been suggested that shorter denning period increases bear scavenging on kills of Eurasian lynx Lynx lynx, which leads to increased lynx predation rate on ungulates and may even threaten this apex predator (Krofel \& Jerina, 2016).

With our study on bear denning behaviour, we highlight another potential modification of carnivore life-history traits that can be triggered by provisioning of anthropogenic foods to carnivores (reviewed in Newsome et al., 2015). We also add to the growing list of recorded side-effects of bear supplemental feeding (Penteriani et al., 2010; Kavčič et al., 2015; Krofel \& Jerina, 2016), which cautions against uncritical application of this management measure. Based on our study, we urge managers to abandon intentional supplemental feeding of bears at least during winter. We also suggest application of measures to reduce bear use of supplemental feeding sites intended for other wildlife. Such measures could include the use of supplemental food not attractive to bears (e.g. hay instead of corn for wild ungulates), providing food in a manner that prevents use by non-target species (e.g. increasing height of bird feeders) or omitting wildlife feeding in core bear areas. We believe these recommendations are relevant for other species of hibernating ursids, especially American black bears, which regularly use anthropogenic food from supplemental feeding sites for wildlife, baited sites for hunting purposes and 
garbage in urban areas (Beckmann \& Berger, 2003; Ziegltrum, 2008; Treves, Kapp \& MacFarland, 2010).

\section{Acknowledgements}

This study was partly financed by the Slovenian Environmental Agency (project no. 2523-08-100547) and Slovenian Research Agency (J4-7362). M. Krofel was supported by the research grant from the Pahernik foundation. We are grateful to Slovenia Forest Service personnel for help with bear captures and to S.M. Wilson and two anonymous reviewers for reviewing the early draft and improving the English.

\section{References}

Amstrup, S.C. (1993). Human disturbances of denning Polar bears in Alaska. Arctic 46, 246.

Beckmann, J.P. \& Berger, J. (2003). Rapid ecological and behavioural changes in carnivores: the responses of black bears (Ursus americanus) to altered food. J. Zool. 261, 207.

Ciarniello, L.M., Boyce, M.S., Heard, D.C. \& Seip, D.R. (2005). Denning behavior and den site selection of grizzly bears along the Parsnip River, British Columbia, Canada. Ursus 16, 47.

Ciarniello, L.M., Boyce, M.S., Seip, D.R. \& Heard, D.C. (2009). Comparison of grizzly bear Ursus arctos demographics in wilderness mountains versus a plateau with resource development. Wildl. Biol. 15, 247.

Clevenger, A.P., Purroy, F.J. \& Pelton, M.R. (1990). Movement and activity patterns of a European brown bear in the Cantabrian Mountains, Spain. Int. C. Bear 8, 205.

Clevenger, A.P., Purroy, F.J. \& Pelton, M.R. (1992). Foodhabits of brown bears (Ursus arctos) in the Cantabrian Mountains, Spain. J. Mammal. 73, 415.

Dobey, S., Masters, D.V., Scheick, B.K., Clark, J.D., Pelton, M.R. \& Sunquist, M.E. (2005). Ecology of Florida black bears in the Okefenokee-Osceola ecosystem. Wildl. Monogr. 158, 1.

Evans, A.L., Sahlén, V., Støen, O.-G., Fahlman, Å., Brunberg, S., Madslien, K., Fröbert, O., Swenson, J.E. \& Arnemo, J.M. (2012). Capture, anesthesia, and disturbance of free-ranging brown bears (Ursus arctos) during hibernation. PLoS One 7, e40520.

Evans, A.L., Singh, N.J., Friebe, A., Arnemo, J.M., Laske, T.G., Fröbert, O., Swenson, J.E. \& Blanc, S. (2016). Drivers of hibernation in the brown bear. Front. Zool. 13, 1.

Florant, G.L. \& Healy, J.E. (2012). The regulation of food intake in mammalian hibernators: a review. J. Comp. Physiol. B. 182, 451 .

Friebe, A., Swenson, J.E. \& Sandegren, F. (2001). Denning chronology of female brown bears in central Sweden. Ursus 12, 37 .

Graham, K. \& Stenhouse, G.B. (2014). Home range, movements, and denning chronology of the grizzly bear (Ursus arctos) in West-Central Alberta. Can. Field Nat. 128, 223.
Harlow, H.J. (1995). Fasting biochemistry of representative spontaneous and facultative hibernators: the white-tailed prairie dog and the black-tailed prairie dog. Physiol. Zool. 68, 915.

Haroldson, M.A., Ternent, M.A., Gunther, K.A. \& Schwartz, C.C. (2002). Grizzly bear denning chronology and movements in the Greater Yellowstone Ecosystem. Ursus 13, 29.

Hellgren, E.C. (1998). Physiology of hibernation in bears. Ursus 10, 467.

Hissa, R. (1997). Physiology of the European brown bear (Ursus arctos arctos). Ann. Zool. Fenn. 34, 267.

Huber, D. \& Roth, H.U. (1997). Denning of brown bears in Croatia. Int. C. Bear 9, 79.

Jerina, K., Jonozovič, M., Krofel, M., Stergar, M. \& Videmšek, U. (2012). Factors affecting brown bear habituation to humans: a GPS telemetry study. Final report. Biotechnical Faculty, University of Ljubljana, Ljubljana, Slovenia.

Kavčič, I., Adamič, M., Kaczensky, P., Krofel, M. \& Jerina, K. (2013). Supplemental feeding with carrion is not reducing brown bear depredations on sheep in Slovenia. Ursus 24, 111.

Kavčič, I., Adamič, M., Kaczensky, P., Krofel, M., Kobal, M. \& Jerina, K. (2015). Fast food bears: brown bear diet in a human-dominated landscape with intensive supplemental feeding. Wildl. Biol. 21, 1.

Krofel, M. \& Jerina, K. (2016). Mind the cat: conservation management of a protected dominant scavenger indirectly affects an endangered apex predator. Biol. Conserv. 197, 40.

Krofel, M., Jonozovič, M. \& Jerina, K. (2012). Demography and mortality patterns of removed brown bears in a heavily exploited population. Ursus 23, 91.

Linnell, J.D.C., Swenson, J.E., Andersen, R. \& Barnes, B. (2000). How vulnerable are denning bears to disturbance? Wildl. Soc. Bull. 28, 400.

López-Alfaro, C., Robbins, C.T., Zedrosser, A. \& Nielsen, S.E. (2013). Energetics of hibernation and reproductive trade-offs in brown bears. Ecol. Model. 270, 1.

Manchi, S. \& Swenson, J.E. (2005). Denning behaviour of Scandinavian brown bears Ursus arctos. Wildl. Biol. 11, 123.

McLoughlin, P.D., Cluff, H.D. \& Messier, F. (2002). Denning ecology of barren-ground grizzly bears in the central Arctic. $J$. Mammal. 83, 188.

Mertzanis, Y., Ioannis, I., Mavridis, A., Nikolaou, O., Riegler, S., Riegler, A. \& Tragos, A. (2005). Movements, activity patterns and home range of a female brown bear (Ursus arctos, L.) in the Rodopi Mountain Range, Greece. Belg. J. Zool. 135, 217.

Miller, S.D. (1990). Denning ecology of brown bears in Southcentral Alaska and comparisons with a sympatric black bear population. Int. C. Bear 8, 279.

Naves, J., Fernández-Gil, A. \& Delibes, M. (2001). Effects of recreation activities on one brown bear family group in Spain. Ursus 12, 135.

Newsome, T.M., Dellinger, J.A., Pavey, C.R., Ripple, W.J., Shores, C.R., Wirsing, A.J. \& Dickman, C.R. (2015). The 
ecological effects of providing resource subsidies to predators. Glob. Ecol. Biogeogr. 24, 1.

Nores, C., Ballesteros, F., Blanco, J.C., Garcia-Serrano, A., Herrero, J. \& Palomero, G. (2010). Evidence of nonhibernation in Cantabrian brown bears. Acta Theriol. 55, 203.

Oli, M.K., Jacobson, H.A. \& Leopold, B.D. (1997). Denning ecology of black bears in the White River National Wildlife Refuge, Arkansas. J. Wildl. Manag. 61, 700.

Oro, D., Genovart, M., Tavecchia, G., Fowler, M.S. \& MartínezAbraín, A. (2013). Ecological and evolutionary implications of food subsidies from humans. Ecol. Lett. 16, 1501.

Peirce, K.N. \& Van Daele, L.J. (2006). Use of a garbage dump by brown bears in Dillingham, Alaska. Ursus 17, 165.

Penteriani, V., Delgado, M.D.M. \& Melletti, M. (2010). Don't feed the bears!. Oryx 44, 169.

Pigeon, K. (2011). Denning behaviour and climate change: linking environmental variables to denning of grizzly bears in the Rocky Mountains and boreal forest of Alberta, Canada. Annual report. Foothills Research Institute Grizzly bear program, Hinton, Alberta.

Rayl, N.D., Fuller, T.K., Organ, J.F., McDonald, J.E., Otto, R.D. \& Mahoney, S.P. (2014). Den abandonment and transitional day bed use by black bears Ursus americanus in Newfoundland. Wildl. Biol. 20, 222.

Schoen, J.W., Beier, L.R., Lentfer, J.W. \& Johnson, L.J. (1987). Denning ecology of brown bears on Admiralty and Chichagof islands. Int. C. Bear 7, 293.

Servheen, C. (1983). Grizzly bear food-habits, movements, and habitat selection in the Mission Mountains, Montana. J. Wildl. Manag. 47, 1026.

Servheen, C. \& Cross, M. S. (2010). Climate change impacts on grizzly bears and wolverines in the northern US and transboundary Rockies: strategies for conservation. Report on a workshop held Sept 2010 in Fernie, British Columbia, Canada.

Seryodkin, I.V., Kostyria, A.V., Goodrich, J.M., Miquelle, D.G., Smirnov, E.N., Kerley, L.L., Quigley, H.B. \& Hornocker, M.G. (2003). Denning ecology of brown bears and Asiatic black bears in the Russian Far East. Ursus 23, 153.
Skuban, M., Find'o, S. \& Kajba, M. (2016). Human impacts on bear feeding habits and habitat selection in the Pol'ana Mountains, Slovakia. Eur. J. Wildl. Res. 62, 353.

Steyaert, S.M.J.G., Kindberg, J., Jerina, K., Krofel, M., Stergar, M., Swenson, J.E. \& Zedrosser, A. (2014). Behavioral correlates of supplementary feeding of wildlife: can general conclusions be drawn? Basic Appl. Ecol. 15, 669.

Swenson, J.E., Sandegren, F., Brunberg, S. \& Wabakken, P. (1997). Winter den abandonment by brown bears Ursus arctos: causes and consequences. Wildl. Biol. 3, 35.

Tietje, W.D. \& Ruff, R.L. (1980). Denning behavior of black bears in boreal forest of Alberta. J. Wildl. Manag. 4, 858.

Treves, A., Kapp, K.J. \& MacFarland, D.M. (2010). American black bear nuisance complaints and hunter take. Ursus 21, 30.

Van Daele, L.J., Barnes, V.G. \& Smith, R.B. (1990). Denning characteristics of brown bears on Kodiak Island, Alaska. Int. C. Bear 8, 257.

Wooding, J.B. \& Hardisky, T.S. (1992). Denning by Black Bears in Northcentral Florida. J. Mammal. 73, 895.

Ziegltrum, G.J. (2008). Impacts of the black bear supplemental feeding program on ecology in western Washington. Hum. Wildl. Confl. 2, 153.

\section{Supporting Information}

Additional Supporting Information may be found in the online version of this article:

Table S1. Measurements of cave den sites used by brown bear Ursus arctos in Slovenia.

Table S2. Aspect of bear dens' entrances.

Table S3. Data extracted from the review of studies on wild brown bear denning.

Figure S1. Schematic figure of bear den measurements.

Figure S2. Entrance into a typical brown bear den (natural cave) in Slovenia. 